\title{
PENGARUH PENGUNGKAPAN \\ CORPORATE SOCIAL RESPONSIBILITY (CSR) DAN \\ PROFITABILITAS TERHADAP NILAI PERUSAHAAN DENGAN STRUKTUR MODAL SEBAGAI VARIABEL PEMODERASI \\ (Studi Pada Perusahaan Food and Beverage Tahun 2013-2017)
}

\author{
Anggita Langgeng Wijaya ${ }^{1)}$, Erlita Listyana Pancawati ${ }^{2}$ \\ Fakultas Ekonomi dan Bisnis Universitas PGRI Madiun \\ gonggeng14@gmail.com ${ }^{1)}$, erlitalistyanapanca@gmail.com²)
}

\begin{abstract}
The implementation of Corporate Social Responsibility is now very necessary. The purpose of this study is to explain the effect of CSR Disclosure (XI) on Company Value (Y), Profitability (X2) on Company Value (Y), and the role of Capital Structure (Z) as a moderating variable of the influence of CSR (XI) and Profitability (X2) of Company Value (Y).The sample in this study is a food and beverage company listed on the Indonesia Stock Exchange (BEI), in 2013-2017 whose financial statements contain corporate social responsibility activities. Data is taken through financial statements that will be sampled according to the desired criteria. This analysis technique uses statistical analysis, and regression analysis. The results of this study indicate that the Corporate Social Responsibility (CSR) variable has a positive and significant effect on Company Value, the Profitability Variable has a positive and significant effect on Company Value, the Capital Structure Variable significantly strengthens the effect of Corporate Social Responsibility (CSR) on Company Value, the Capital Structure Variable significantly strengthens the effect of Profitability on Company Value.

Keywords: Corporate Social Responsibility (CSR) Disclosure, Profitability, Capital Structure, Company Value.
\end{abstract}

\begin{abstract}
Abstrak
Perkembangan dunia bisnis saat ini mengalami kemajuan yang sangat pesat serta persaingan yang begitu ketat. Saat perusahaan semakin berkembang, maka tingkat kesenjangan sosial dan kerusakan lingkungan semakin tinggi karena adanya aktivitas perusahaan yang tidak dapat terkendali terhadap berbagai sumber daya agar dapat meningkatkan perolehan laba perusahaan. Karena itu penerapan Corporate Social Responsibility sekarang ini sangat diperlukan. Tujuan Penelitian ini adalah untuk menjelaskan pengaruh Pengungkapan CSR(XI) terhadap Nilai Perusahaan(Y), Profitabilitas(X2) terhadap Nilai Perusahaan(Y), serta peran Struktur Modal(Z) sebagai variabel pemoderasi dari pengaruh CSR(XI) dan Profitabilitas(X2) terhadap Nilai Perusahaan(Y).
\end{abstract}

Kata Kunci: Corporate Social Responsibility, Profitabilitas, Nilai Perusahaan, Struktur modal

\section{PENDAHULUAN}

Menghadapi persaingan bisnis saat ini yang kian ketat di era pasar bebas perusahaan dituntut agar manajemennya kuat dan profesional supaya mendapat survive sehingga berkembang. Ini menyebabkan perusahaan harus mengembangkan strategi tepat agar mampu mempertahankan eksistensinya, Badan Usaha tiak dapat terpisahkan dari masyarakat sebagai pihak eksternalnya. Hubungan timbal balik perusahaan dengan masyarakat yang tidak dapat dipisahkan. Perusahaan yang tidak terdukung oleh pengawasan yang baik akan, menimbulkan masalahan-masalah didalam kegiatan usahanya. Mustafa Cintya dan Handayani (2014) .

Dewasa ini, peringatan tentang kesadaran untuk menjaga lingkungan serta pentingnya CSR sudah diatur didalam UU Perseroan Terbatas No.40 pasal 74 tahun 2007, "menerangkan bahwa perusahaan didalam melaksanakan kegiatan bisnis yang berhubungan dengan SDA diwajibkan untuk menerapkan tanggung jawab sosial serta lingkungaan".

CSR merupakan bentuk tanggungjawab perusahaan untuk memperbaiki kerusakan lingkungan dan kesenjangan sosial yang terjadi akibat proses aktivitas perusahaannya. Image 
perusahaan akan meningkat apabila semakin banyaknya bentuk pertanggungjawaban terhadap lingkungan yang telah dilakukan. Citra yang baik di masyarakat akan menarik investor supaya menanamkan modalnya pada perusahaan, profitabilitas perusahaan akan naik dan nilai perusahaan akan meningkat. Retno dan Priantinah (2012)

Penelitian mengenai Corporate

Social Responsibility terhadap Nilai Perusahaan menunjukkan hasil tidak konsisten. Penelitian yang dilakukan Rosiana (2013) pengungkapan Corporate Social Responsibility berpengaruh signifikan terhadap Nilai Perusahaan. Sedangkan penelitian dari Setyaningrum (2015), menyatakan bahwa CSR tidak berpengaruh terhadap nilai perusahaan.

Adanya ketidak konsistenan, oleh karenanya dalam penelitian ini dimasukkan struktur modal sebagai variabel pemoderasi yang diduga memoderasi atau tidak memoderasi interaksi antara Corporate Social Responsibility terhadap nilai perusahaan. Struktur modal diduga ikut berpengaruh karena menurut Suastini, Purbawagsa dan Rahyuda (2016), keputusan struktur modal bersumber dari dana eksternal perusahaan yang bisa mempengaruhi nilai perusahaan.

Berdasarkan penjabaran tersebut, maka penulis memilih judul "Pengaruh Pengungkapan Corporate Social Responsibility (CSR)dan Profitabilitas terhadap Nilai Perusahaan dengan Struktur Modal sebagai Variabel Pemoderasi (Studi pada Perusahaan Food and Beverage yang terdaftar di Bursa Efek Indonesia periode 2013-2017)"
KAJIAN
TEORI
DAN
PENGEMBANGAN HIPOTESA
Kajian Teori

\section{Signaling Theory}

Signaling theory berisi tentang dorongan perusahaan tuk memberi informasi laporan keuangan perusahaan pada pihak luar (investor, debitur, masyarakat, dan pihak yang berkepentingan lainnya). Dorongan itu terjadi dikarenakan ada asimetri informasi antara perusahaan dan pihak luar. Anggitasari (2012).

\section{Tanggungjawab Sosial Perusahaan}

CSR merupakan bentuk tanggungjawab yang dilakukan untuk memperbaiki permasalahan sosial dan kerusakan lingkungan dikarenakan aktivitas operasional yang perusahaan terhadap lingkungan. Kusumadilaga (2010).

\section{Profitabilitas}

Menurut Kasmir (2008:196), "rasio profitabilitas ialah rasio untuk menilai kemampuan perusahaan dalam mencari keuntungan. Rasio ini memberi ukuran tingkatan efektivitas manajemen perusahaan. Ini diketahui oleh laba yang dihasilkan dari penjualan dan pendapatan investasi”.

\section{Nilai Perusahaan}

Nilai perusahaan dalam penelitian ini diartikan sebagai nilai pasar, karena pemegang saham akan makmur apabila harga saham suatu perusahaan dalam jumlah maksimum dan hal ini akan meningkatkan nilai perusahaan. Mandansari, Kamaliah dan Hanif (2013). Nilai perusahaan diindikasikan dengan PBV. PBV tinggi, akan menyebabkan masyarakat mempercayai atas prospek perusahaan di masa depan. Sambora, Handayani dan Rahayu (2014).

\section{Struktur Modal}

Struktur modal merupakan perbandingan atau perimbangan jumlah hutang berjangka panjang pada modalnya 
sendiri. Karenanya, struktur modal diukur melalui DER. DER ialah rasio sebagai pengukur tingkat leverage terhadap total shareholder's ekuitas yang ada di perusahaan. Hermuningsih (2012)

\section{Pengembangan Hipotesa}

\section{Pengaruh Corporate Social Responsibility (CSR)terhadap Nilai} Perusahaan

M Retno dan Priantinah (2012), meleliti tentang Pengaruh Good Corporate Gonvernance dan Pengungkapan Corporate Social Responsibility Terhadap Nilai Perusahaan, hasilnya adalah Pengungkapan Csr, berpengaruh positif dan tidak signifikan terhadap nilai Perusahaan.

\section{$\mathrm{H}_{1}$ : Corporate Social Responsibility (CSR) berpengaruh positif terhadap Nilai Perusahaan}

2. Pengaruh Profitabilitas terhadap Nilai Perusahaan

Mardiyanti, Ahmad dan Putri (2012), meneliti tentang Pengaruh kebijakan dividen, Kebijakan hutang dan Profitabilitas terhadap Nilai Perusahaan Manufaktur dengan hasil Profitabilitas mempengaruhi nilai perusahaan.

\section{$\mathrm{H}_{2}$ : Profitabilitas berpengaruh positif terhadap Nilai Perusahaan}

\section{Pengaruh Struktur Modal} Sebagai Variabel Pemoderasi dalam HubunganCorporate Social Responsibility (CSR) dan Nilai Perusahaan

"Struktur modal pada perusahaan yang bisa mempengaruhi pengeluaran pada pembiayaan CSR Mengacu pada Jensen (1986) dan Zweibel (1996), menyimpulkan jika saat perusahaan punya hutang bunga yang tinggi kemampuan manajer untuk menginvestasi lebih pada program CSR semakin terbatas", H3. Prof. Dr. Hj.

Rahmawati, M.Si., Ak

\section{$\mathrm{H}_{3}$ : Struktur Modal dapat Memperkuat Nilai Perusahaan.}

4. Pengaruh Struktur Modal Sebagai Variabel Pemoderasi dalam HubunganProfitabilitas dan Nilai Perusahaan Sari, Idrus dan Yuliana (2018), meneliti tentang Pengaruh Struktur modal dan profitabilitas terhadap nilai perusahaan dengan pengungkapan corporate social responsibility sebagai variabel moderating, dengan hasil Struktur modal mempunyai pengaruh signifikan terhadap nilai perusahaan melalui profitabilitas

\section{$\mathrm{H}_{4}$ : Struktur Modal dapat Memperkuat Nilai Perusahaan.}

\section{METODE PENELITIAN}

Penelitian dilakukan pada Bursa Efek Indonesia dan situs resmi perusahaan Food and Beverage. Objek dalam penelitian adalah perusahaan Food and Beverage dengan data laporan keberlanjutan (sustainability report) dan laporan tahunan periode 2013-2017. Jenis penelitian ini merupakan metode penelitian kuantitatif. Populasi penelitian adalah 18 perusahaan Food and Beverage yang terdaftar di Bursa Efek Indonesia (BEI) periode 2013-2017. Sampel 
penelitian dipilih dengan teknik purposive sampling dengan kriteria yang telah ditetapkan sehingga diperoleh sampel sejumlah 12 perusahaan kemudian dikalikan 5 tahun dan akhirnya diperoleh total sampel sebanyak 60 .

\section{Tabel 2. Deskripsi Sampel}

\begin{tabular}{|c|c|c|}
\hline No & $\begin{array}{l}\text { Kode } \\
\text { Saham }\end{array}$ & Daftar Emitten \\
\hline 1. & AISA & Pt. Tiga Pilar Sejahtera Food.Tbk \\
\hline 2. & CEKA & Pt. Wilmar Cahaya Indonesia. Tbk \\
\hline 3. & DLTA & Pt. Delta Djakarta. Tbk \\
\hline 4. & ICBP & $\begin{array}{l}\text { Pt. Indofood Cbp Sukses Makmur. } \\
\text { Tbk }\end{array}$ \\
\hline 5. & INDF & $\begin{array}{l}\text { Pt. Indofood Sukses Makmur. Tbk } \\
\text { Dan Entitas Anaknya }\end{array}$ \\
\hline 6. & MLBI & Pt. Multi Bintang Indonesia. Tbk \\
\hline 7. & MYOR & Pt. Mayora Indah. Tbk \\
\hline 8. & PSDN & Pt. Prashida Aneka Niaga. Tbk \\
\hline 9. & ROTI & Pt. Nippon Indosari Corpindo. Tbk \\
\hline 10. & SKBM & Pt. Sekar Bumi. Tbk \\
\hline 11. & SKLT & Pt. Sekar Laut. Tbk \\
\hline 12. & ULTJ & $\begin{array}{l}\text { Pt. Ultrajaya Milk Industry \& } \\
\text { Trading Company. Tbk }\end{array}$ \\
\hline
\end{tabular}

Teknik Analisis Data

Statistik Deskriptif

Statistik deskriptif, digunakan

untuk mengetahui tingkat pengungkapan

Corporate Social Responsibility (CSR),

Profitabilitas dan Struktur Modalsebagai

Variabel Pemoderasi.

\section{Uji Asumsi Klasik}

\section{Uji Normalitas}

Ghozali Imam (2013), "uji normalitas data, merupakan langkah awal yang perlu dilakukan pada setiap analisis multivariate terutama jika tujuannya adalah infensi, apabila terdapat normalitas, maka residual akan terdistribusikan secara normal dan independen".

\section{Uji Multikolineritas}

Ghozali Imam (2013), “ uji multikolinieritas adalah pengujian yang dilakukan untuk menguji apakan model regresi terjdi korelasi antar variabel independen (bebas)".

\section{Uji Autokorelasi}

Ghozali Imam (2013), "pengujian autokorelasi digunakan untuk menguji apakah dalam model regresi linier ada korelasi antara kesalahan penganggu pada periode tahun berjalan dengan kesalahan penganggu pada periode sebelumnya, jika ada korellasi maka dinamakan ada problem autokorelasi”.

\section{Uji Heteroskedastisitas}

Ghozali Imam (2013), “ uji heteroskedastisitas adalah pengujian yang dilakukan untuk mengetahui apakah dalam model regresi terjadi ketidaksamaan variance dari residual satu pengamatan ke pengaatan lain, jika pengamatan dari satu pengamatan ke pengamatan lain tetap, maka disebut dengan terjadinya Homoskedastisitas dan jikaa berbeda disebut Heteroskedastisitas".

\section{Pengujian Hipotesis}

Sarwono (2012:1), "analisis regresi ialah studi mengenai pengaruh variabel dependen dengan satu atau lebih variabel independen".

\section{a. Uji Regresi Linier Berganda}

Analisi regresi linier berganda, digunakan untuk menguji pengaruh satu variabel independen (X) terhadap satu variabel dependen (Y).

b. Kooefisien Determinasi $\left(\mathbf{R}^{\mathbf{2}}\right)$ Algifari (2009 : 31), "pengukuran koefisien determinasi $\left(\mathrm{R}^{2}\right)$ adalah cara utama yang digunakan untuk mengetahui apakah ada hubungan antara dua variable, koefisien determinasi yang diperoleh pada sebuah sampel disebut koefisien determinasi sampel".

c. Uji t (Parsial)

Menurut Ghozali (2013 : 64 ), “uji parsial digunakan untuk mengetahui apakah dua sampel yang tidak berhubungan memiliki nilai rata-rata yang berbeda". 
d. Moderated Regression Analysis (MRA)

Ghozali (2013:229), "moderated

Regression Analysis (MRA),

digunakan untuk menguji efek

moderasi dalam persamaan regresi

liniernya secara bertahap, dalam

Moderated Regression Analysis

(MRA) menggunakan pendekatan analitik yang mempertahankan integritas sample dan memberikan dasar untuk mengontrol pengaruh variabel moderasi”.

\section{HASIL DAN PEMBAHASAN}

\section{Statistik Deskriptif}

Tabel 4.2. Uji Statistik Deskriptif

\begin{tabular}{lccrrr}
\hline & N & Min & Max & Mean & $\begin{array}{r}\text { Std. } \\
\text { Devitatio } \\
\end{array}$ \\
& & & & & $\mathrm{n}$ \\
\hline Csr & 5 & .00 & 19.05 & 5.5620 & 5.28566 \\
Profitabilita & 5 & -.13 & .65 & .1565 & .12105 \\
s & 5 & .18 & 865.0 & 77.645 & 141.1422 \\
Nilai & 5 & & 0 & 3 & 8 \\
perusahaan & 5 & & & & \\
Valid N & 5 & & & & \\
(listwise) & 5 & & & & \\
& 5 & & & & \\
\hline Surer
\end{tabular}

Sumber: Data diolah 2019.

Hasil Tabel diatas menunjukkan:

Corporate Social Responsibility

Tabel diatas menunjukkan variabel

Corporate Social Responsibility (CSR) memiliki nilai minimum 0,00 , nilai maximum 19,05. Sedangkan untuk nilai rata-rata sebesar 5,5620 dengan standar deviasi atau simpangan baku sebesar 5,28566 .

\section{Profitabilitas}

Tabel diatas menunjukkan variabel profitabilitas memiliki nilai minimum 0,13 , nilai maximum 0,65 . Sedangkan nilai rata-rata sebesar 0,1565 dengan standar deviasi atau simpangan baku sebesar 0,12105 .

\section{Nilai Perusahaan}

Tabel diatas menunjukkan variabel nilai perusahaan memiliki nilai minimum 0,18,nilai maximum 865.00. Sedangkan untuk nilai rata-rata sebesar 77.6453 dengan standar deviasi atau simpangan baku sebesar 141.14228.

\section{Uji Asumsi Klasik}

Uji Normalitas

Uji normalitas pertama data (N) 60 tidak berdistribusi normal sehingga dilakukan elminasi data outlier. Sehingga tersisa $55(\mathrm{~N})$ data.

Tabel 4.3. Uji Normalitas

One-Sample Kolmogrov-Smirnov Test

\begin{tabular}{|c|c|}
\hline & $\begin{array}{c}\text { Unstandardized } \\
\text { Residual }\end{array}$ \\
\hline $\mathrm{N}$ & 55 \\
\hline \multirow[t]{2}{*}{ Normal Paramaters ${ }^{\text {a.b }}$} & .0000000 \\
\hline & .93 .56633889 \\
\hline Devitation & .091 \\
\hline Most Extreme Differences & .091 \\
\hline \multirow[t]{2}{*}{ Absolute } & -.090 \\
\hline & .091 \\
\hline Positive & $.200^{\text {c.d }}$ \\
\hline \multicolumn{2}{|l|}{ Negative } \\
\hline \multicolumn{2}{|l|}{ Test Statistic } \\
\hline \multicolumn{2}{|l|}{ Asymp. Sig. (2-tailed) } \\
\hline \multicolumn{2}{|l|}{ Sumber: Data diolah 2019.} \\
\hline \multirow{4}{*}{\multicolumn{2}{|c|}{$\begin{array}{l}\text { Berdasarkan hasil pengujian pada } \\
\text { tabel diatas mendapatkan hasil Asymp. } \\
\text { Sig. (2-tailed) sebesar } 0,200 \text {. Nilai tersebut } \\
\text { lebih besar dari } 005 \text { Sehingoa }\end{array}$}} \\
\hline & \\
\hline & \\
\hline & \\
\hline $\begin{array}{l}\text { kesimpulannya mod } \\
\text { distribusi nilai residu }\end{array}$ & $\begin{array}{l}\text { el penelitian memiliki } \\
\text { al yang normal. }\end{array}$ \\
\hline
\end{tabular}

Uji Multikolinearitas

Tabel 4.4. Uji Multikolinearitas

\begin{tabular}{llcc}
\hline & & \multicolumn{2}{c}{ Collinearity Statistics } \\
Model & & Tolerance & VIF \\
\hline 1 & (Constant) & & \\
& CSR & 1.000 & 1.000 \\
& Profitabilitas & 1.000 & 1.000
\end{tabular}

Sumber: Data diolah 2019.

Hasil pengujian terhadap korelasi antar variabel independen dapat diambil kesimpulannya bahwa tidak terdapat korelasi antar variabel independen.

\section{Uji Heteroskedastisitas}

Gambar 4.1. Uji Heteroskedastisitas 


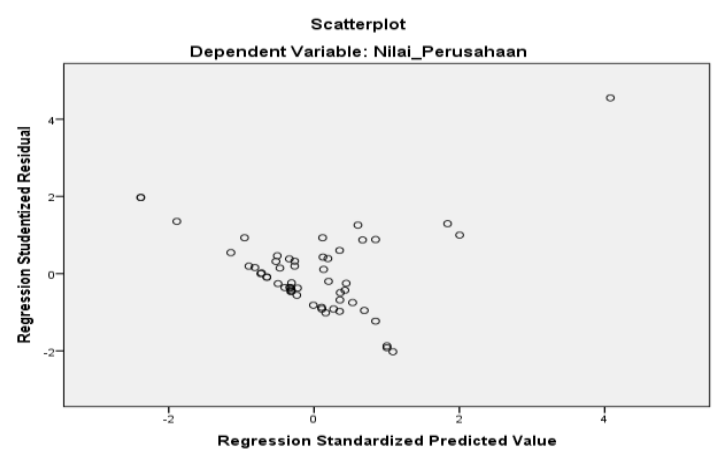

Berdasarkan tabel di atas terlihat bahwa pola data menyebar di atas dan di bawah garis horisontal 0; sehingga dapat disimpulkan bahwa, model regresi tidak terjadi masalah heteroskedastisitas.

\section{Uji Autokorelasi}

Tabel 4.5. Uji Autokorelasi

\begin{tabular}{|c|c|c|c|c|c|c|c|c|c|}
\hline & & & & & $\left(\mathbf{R}^{2}\right.$ & & & & \\
\hline & & & Adjusted & $\begin{array}{c}\text { Std. } \\
\text { Error of }\end{array}$ & $\begin{array}{c}\text { Durbin } \\
-\end{array}$ & & Adjusted & Std. & \\
\hline Mo & & $\mathrm{R}$ & $\mathrm{R}$ & The & Watson & Square & $\mathrm{R}$ & Error of & Watson \\
\hline Del & $\mathrm{R}$ & Square & Square & Eslimate & & & & & \\
\hline
\end{tabular}

Sumber: Data diolah 2019.

Nilai durbin watson pada output pengujian sebesar 1,302. Berdasarkan tabel durbin watson, diketahui nilai $\mathrm{dU}$ untuk jumlah data 60 yang di outliyer menjadi 55 data perusahaan yang di hitung per tahun dan jumlah variabel independen 2 yaitu 1,6406 sehingga nilai 4-dU sebesar 2,3594 (4-1,6406). Nilai-DW berada diantara dU dan 4-dU. Sehingga kesimpulanya tidak terdapat autokorelasi pada model penelitian.

\section{Pengujian Hipotesis}

Regresi Linier Berganda

Tabel 4.6. Uji Regresi Linier

1. Menunjukkan bahwa konstanta bernilai -61.338 berarti nilai perusahaan adalah sama dengan nol atau tetap, maka nilai integritas sebesar -61.338.

2. Koefisien regresi variabel CSR bernilai 0,420, berarti terdapat hubungan yang positif atau searah dengan nilai perusahaan sebesar 0,420 .

3. Nilai koefisien regresi variabel Profitabilitas bernilai 872.908 , berarti terdapat hubungan yang positif atau searah dengan nilai perusahaan sebesar 872.908.

Koefisien Determinasi $\left(\mathbf{R}^{2}\right)$

Tabel 4.7. Uji Koefisien Determinasi

Model R Eslimate

$\begin{array}{llllll}1 & .74 & .561 & .544 & 95.34872 & 1.302 \\ & 9^{\mathrm{a}} & & & & \end{array}$

Sumber: Data diolah 2019

Menunjukkan nilai Adjusted $R$

Squaresebesar 0,544. Nilai tersebut menunjukkan bahwa variabel Corporate Social Responsibility (CSR) dan Profitabilitas mampu memprediksi variabel Nilai Perusahaan sebesar 0,544.

Uji Parsial (Uji t)

Tabel 4.8. Uji Parsial (Uji t)

Coefficients $^{\mathbf{a}}$

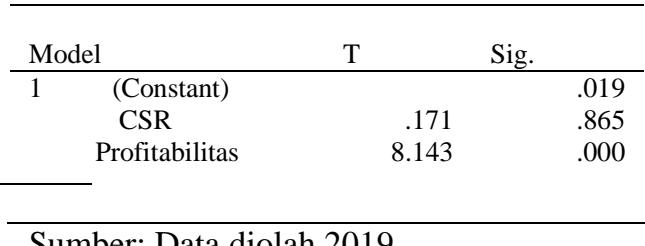

sią) thitung CSR -2.431 dengan nilai sig 0,865 lebih kecil dari nilai alpha 0,05. CSR secara parsial tidak berpengaruh terhadap Nilai Perusahaan.

Sumber: Data diolah 2019.

b) thitung Profitabilitas 0,171 dengan nilai sig 0,000 lebih kecil dari nilai alpha

Dari Tabel diatas diketahui bahwa: 
0,05. Profitabilitas secara parsial berpengaruh positif terhadap Nilai

Perusahaan.

Persamaan Moderated Regression

Analysis (MRA)

Tabel 4.9. Uji MRA

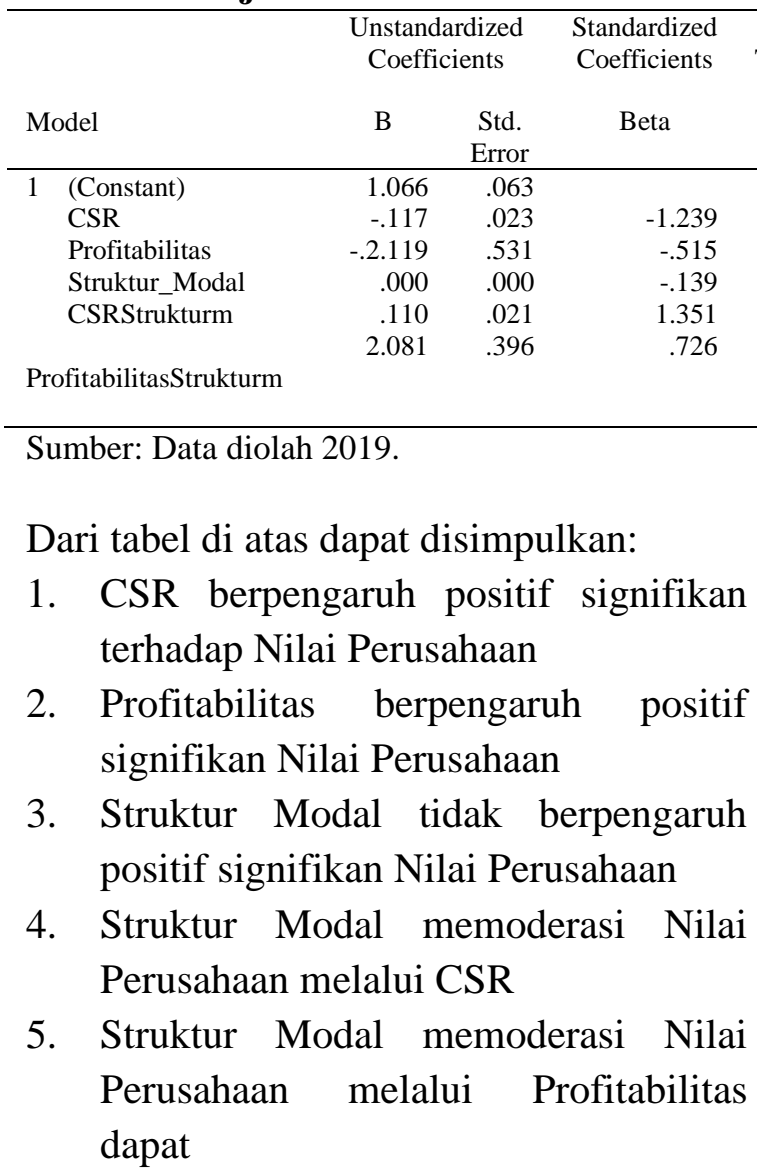

HASIL DAN PEMBAHASAN

\section{Pembahasan}

1. Pengaruh Corporate Social Responsibility (CSR) terhadap Nilai Perusahaan

Hasil menunjukkan nilai sig sebesar 0,000 (lebih kecil dari alpha 0,05) dengan nilai koefisien beta sebesar 1.239. Menunjukkan bahwa CSR berpengaruh positif signifikan terhadap Nilai Perusahaan. Sehingga disimpulkan bahwa hipotesis pertama diterima.

2. Pengaruh Profitabilitas terhadap Nilai Perusahaan
Hasil menunjukkan nilai sig sebesar 0,000 (lebih kecil dari alpha 0,05) dengan nilai koefisien beta sebesar 0,515. Menunjukkan bahwa Profitabilitas berpengaruh positif signifikan terhadap Nilai Perusahaan. Sehingga disimpulkan bahwa hipotesis kedua diterima.

\$ร Pengaruh Corporate Social Responsibility (CSR) terhadap Nilai ${ }_{000}$ Perusahaan dengan Struktur Modal .000 sebagai Variabel Pemoderasi

.144 Hasil menunjukkan nilai sig sebesar .000 0,000 (lebih kecil dari alpha 0,05) dengan nilai thitung sebesar 5.151. Menunjukkan bahwa Struktur Modal memoderasi pengaruh CSR terhadap Nilai Perusahaan.

4. Pengaruh Profitabilitas terhadap Nilai Perusahaan dengan Struktur Modal sebagai Variabel Pemoderasi Hasil pengujian menunjukkan nilai signifikansi sebesar 0,000 (lebih kecil dari alpha 0,05) dengan nilai thitung sebesar 5.248 yang menunjukkan arah positif. Ini menunjukkan bahwa Struktur Modal dapat memoderasi pengaruh Profitabilitas terhadap Nilai Perusahaan.

\section{KESIMPULAN DAN SARAN}

Kesimpulan

Maka dapat disimpulkan bahwa dasil dari penelitian ini adalah sebagai berikut :

1. CSR berpengaruh positif signifikan terhadap Nilai Perusahaan

2. Profitabilitas berpengaruh positif signifikan Nilai Perusahaan

3. Struktur Modal tidak berpengaruh positif signifikan Nilai Perusahaan

4. Struktur Modal memoderasi Nilai Perusahaan melalui CSR

5. Struktur Modal memoderasi Nilai Perusahaan melalui Profitabilitas 


\section{Saran}

Berdasarkan hasil penelitian saya, maka peneliti memberikan saran :

1. Bagi peneliti seterusnya lebih baik lagi jikalau menambahkan periode pengamatannya, karena makin lamanya waktu pengamatan akan makin akurat data penelitiannya.

2. Penelitian seterusnya dapat menambah variabel lain yang lebih berpengaruh pada Variabel Nilai Perusahaan.

3. Penelitian seterusnya lebih baik menambah atau menggunakan variabel moderasi yang lebih berpengaruhnya besar selain variabel Struktur Modal. Misal, Solvabilitas ataupun Rentabilitas, dan Variabel Sebagainya.

\section{DAFTAR PUSTAKA}

Algifari. 2009. Analisis Statistik Bisnis : Badan Penerbit BPFE Yogyakarta

Anggitasari. 2012. "Pengaruh Kinerja

Keuangan Terhadap Nilai

Perusahaan Dengan

Pengungkapan Corporate Social

Responsibility Dan Struktur Good

Corporate Governance Sebagai Variabel Pemoderasi".

Cinthya Mustafa dan Handayani. 2014. "Pengaruh Pengungkapan

Corporate Social Responsibility

Terhadap Kinerja Keuangan Perusahaan Manufaktur.

Dewanggo. 2011. "Pengaruh

Tanggungjawab Sosial Perusahaan

Dalam Laporan Tahunan

Terhadap Harga Saham.

Dewi dan Wirajaya. 2013. "Pengaruh

Struktur Modal, Profitabilitas

DanUkuran Perusahaan Pada Nilai

Perusahaan.

Fajriana dan Priantinah. 2016. "Pengaruh

Corporate Soccial Responsibility,

Keputusan Investasi Dan Struktur

Modal Terhadap Nilai Perusahaan.

Ghozali Imam. 2013. “Aplikasi Analisis
Multivariate Dengan Program

IBM SPSS 21. Semarang : Badan

Penerbit Universitas Diponegoro.

Hermuningsih. 2012. "Pengaruh

Profitabilitas, Size Terhadap Nilai

Perusahaan Dengan Struktur

Modal Sebagai Variabel

Intervening.

Indrawan. 2011. "Pengaruh Corporate

Social Responsibility Terhadap

Kinerja Perusahaan.

Kasmir. 2008. "Analisis laporan

Keuangan" : Diterbitkan oleh

Badan PT RajaGrafindo Persada

Kristi. "Faktor-faktor Yang

Mempengaruhi Corporate Social

Responsibility Pada Perusahaan

Publik Di Indonesia.

Kurnianingsih. 2013. "Pengaruh

Profitabilitas Dan Size Perusahaan

Terhadap Corporate Social

Responsibility

Kusumadilaga. 2010. "Pengaruh

Corporate Social Responsibility

Terhadap Nilai Perusahaan

Dengan Profitabilitas Sebagai

Variabel Moderating.

Lestari dan Ayu. 2016. "Pengaruh

Kepemilikan Manajemen,

Kepemilikan Instusional Dan

Corporate Social Responsibility

Terhadap Nilai Perusahaan Pada

Perusahaan Non Keuangan Go

Public Di Bursa Efek Indonesia.

Mandasari, Kamaliah dan Hanif. 2013.

"The Influence of Corporate

Social Responsibility To Firm

Value With Profitability And

Leverage As A Moderating Variable.

Mardiyati, Ahmad dan Putri. 2012.

"Pengaruh Kebijakan Dividen,

Kebijakan Hutang Dan

Profitabilitas Terhadap Nilai

Perusahaan Manufaktur Yang

Terdaftar Di Bursa Efek Indonesia

(BEI) Periode 2005-2010.

Nurlela dan Islahuddin. 2005. "Pengaruh

Corporate Social Responsibility

Terhadap Nilai Perusahaan

Dengan Prosentase Kepemilikan 
Manajemen Sebagai Variabel Moderating.

Prof. Dr. Hj Rahmawati. 2012. "Teori Akuntansi Keuangan" : Diterbitkan oleh Badan Graha Ilmu

Rakhiemah dan Agustia. "Pengaruh Kinerja Lingkungan Terhadap Corporate Social Responsibility (CSR) Disclosure Daan Kinerja Finansial Perusahaan Manufaktur Yang Terdaftar Di Bursa Efek Indonesia.

Ramadhani. 2012. "Pengaruh Corporate Social Responsibility Terhadap Niali Perusahaan Dengan Prosentase Kepemilikan Manajemen Sebagai Variabel Moderating Pada Perusahaan Manufaktur Yang Terdaftar Di BEI.

Ramona Suci. 2017. "Pengaruh Corporate Social Responsibility Terhadap Nilai Perusahaan Dengan Profitabilitas Sebagai Variabel Moderating.

Retno M dan Priantinah. 2012. "Pengaruh Good Corporate Governance Dan Pengungkapan Corporate Social Responsibility Terhadap Nilai Perusahaan.

Pratama dan Wirawati. 2016. "Pengaruh

Struktur Modal Dan Profitabilitas

Terhadap Nilai Perusahaan

Dengan Kepemilikan Manajerial

Sebagai Pemoderasi.

Puspaningrum yustisia. 2017. "Pengaruh

Corporate Social Responsibility

Dan Kepemilikan Manajerial

Terhadap Nilai Perusahaan

Sebagai Variabel Moderating.

Rosiana, Juliarsa dan Sari. 2013.
"Pengaruh Pengungkapan CSR

Terhadap Nilai Perusahaan Dengan Profitabilitas Sebagai Variabel Pemoderasi.

Sambora, Handayani dan Rahayu. 2014. "Pengaruh Leverage Dan Profitabilitas Terhadap Nilai Perusahaan.

Sari, Idrus dan Yuliana. 2018. "Pengaruh Struktur Modal Dan Profitabilitas Terhadap Nilai Perusahaan Dengan Pengungkapan Corporate Social Responsibility (CSR) Sebagai Variabel Moderating.

Silvia Agustina. 2013. "Pengaruh Profitabilitas Dan Pengungkapan Corporate Social Responsibility Terhadap Nilai Perusahaan.

Setianingrum. 2015. "Pengaruh Corporate Social Responsibility Terhadap Nilai Perusahaan Dengan Profitabilitas Sebagai Variabel Moderasi.

Suastini, Purbawangsa dan Rahyuda. 2016. "Pengaruh Kepemilikan Manajerial Dan Pertumbuhan Perusahaan Terhadap Nilai Perusahaan Pada Perusahaan Manufaktur Di Bursa Efek Indonesia.

Sugiyono. 2011. "Metode Penelitian Kuantitatif, Kualitatif Dan R \& D : Alfabeta Wibowo dan Wartini. 2012. "Efisiensi Modal Kerja, Likuiditas dan Leverage Terhadap Profitabilitas Pada Perusahaan Manufaktur Di BEI.

Wardoyo dan Veronica. 2013. "Pengaruh Good Corporate Governance, Corporate Social Responsibility Dan Kinerja Keuangan Terhadap Nilai Perusahaan". 
